\title{
6 weeks consumption of pure fresh coconut milk caused up-regulation of eNOS and CSE protein expression in middle-aged male rats
}

\author{
Chaweewan Jansakul ${ }^{1,2, *}$, Jomkarn Naphatthalung ${ }^{1,2}$, Sakda Pradab ${ }^{1,2}$, Somruedee Yorsin ${ }^{5}$, \\ Kanyanatt Kanokwiroon ${ }^{3,4}$
}

\begin{abstract}
${ }^{1}$ Faculty of Traditional Thai Medicine, Prince of Songkla University, Hat-Yai, Thailand, ${ }^{2}$ Natural Product Research Centre of Excellence, Prince of Songkla University, Hat-Yai, Thailand, ${ }^{3}$ Department of Biomedical Sciences, Faculty of Medicine, Prince of Songkla University, Hat-Yai, Thailand, ${ }^{4}$ The Excellent Research Laboratory of Cancer Molecular Biology, Prince of Songkla University, Hat-Yai, Thailand, ${ }^{5}$ Faculty of Medicine, Princess of Naradhiwas University, Narathiwas, Thailand
\end{abstract}

\begin{abstract}
Coconut milk (CCM) has been an important cooking ingredient in the Asia-Pacific region since ancient time. Due to its high content of saturated fatty acids, it has been considered atherogenic. We have tested if chronic consumption of fresh coconut milk by middle-aged male rat affects vascular function, plasma glucose and lipid profiles. Compared to control, CCM caused lower maximal contraction to phenylephrine of thoracic aortic rings and increased relaxation to acetylcholine that was abolished by $N^{\mathrm{G}}$-nitro-L-arginine (L-NA) or disruption of the endothelium. DL-propargylglycine caused slight increase in baseline tension of L-NA treated aortic rings of CCM-treated rats and produced higher contractile response of the aortic rings to low concentrations of phenylephrine. The aortic eNOS- and cystathionine- $\gamma$-lyase(CSE) proteins expression of the CCM-treated rats were also higher than in controls. Except for lower fasting plasma glucose there were no changes in blood chemistry for the CCM treated rats. CCM consumption caused up-regulation of eNOS and CSE protein expression which resulted in increased production of NO and $\mathrm{H}_{2} \mathrm{~S}$ from the blood vessels with attenuation of vasocontraction to phenylephrine and increased relaxation to acetylcholine. These novel benefits may be expected to reduce the development of cardiovascular risk factors in the aging rat.
\end{abstract}

Keywords: Coconut milk. NO. $\mathrm{H}_{2} \mathrm{~S}$. Plasma glucose. Thoracic aorta.

\section{INTRODUCTION}

Age is one of the most important risk factors for cardiovascular disease (Lakatta, 2002; 2015; Lakatta, Levy, 2003), which is the major cause of global death and disability and places a huge burden on healthcare costs (Yazdanyar, Newman, 2009). As population aging is accelerating in nearly all countries of the world, there will soon be more elderly people than children (NIA, 2011; UN, 2013). Thus, it is important that everyone should establish good lifestyle options, and eat diet healthy foods with suitable micronutrients to prolong healthy vascular functions, foster successful aging and reduce their family, social and healthcare burden.

\footnotetext{
* Correspondence: C. Jansakul. Faculty of Traditional Thai Medicine, Prince of Songkla University, Hat-Yai, Thailand 90110. Tel. 66-074-286824. Fax. 66-074-282709. E-mail address: chaweewan.j@psu.ac.th
}

Advancing age is associated with thickening and elastic impairment of vascular wall (Aquaro et al., 2013; Collins, 2014), endothelial dysfunction; decreased vascular eNOS expression and thereby decreased nitric oxide production (Novella et al., 2013). These changes result in reduction of vascular compliance or distensibility (Avolio et al., 1983; Vaitkevicius et al., 1993), which is the early state of pathophysiological changes in the development of cardiovascular disease (Bhayadia et al., 2015; Marchesi et al., 2000; Rudolph et al., 2007).

Recently, it has been accepted that $\mathrm{H}_{2} \mathrm{~S}$ is another gasotransmitter which is generated in blood vessels mainly from L-cysteine by a cystathionine- $\gamma$-lyase (CSE)(Abe, Kimura, 1996; Hosoki, Matsuki, Kimura, 1997). It plays an important role in modulating vascular functions. Deficiency of $\mathrm{CSE}$ reduces $\mathrm{H}_{2} \mathrm{~S}$ production in vascular tissues and leads to endothelial dysfunction and high blood pressure in an age-dependent manner in mice (Yang et al., 2008). 
Cocos nucifera L.belongs to the Arecacaea family. Its endosperm, especially the mature coconut kernel, has been an important ingredient of the Asia-Pacific cuisine for centuries. However, in the last few decades, the high content of saturated fatty acids has led to it being considered an atherogen and thus potentially harmful with respect to development of atherosclerosis in man. Nevertheless, since the main saturated fatty acid components of the coconut oil are medium chains of length $\mathrm{C} 8$ to $\mathrm{C} 12$ which are absorbed via the portal vein (except for $\mathrm{C} 12$, lauric acid, which is partly absorbed via the lymphatic system (Mu, Hoy, 2002)), the atherogenicity of the coconut oil needs to be reconsidered.

About $25 \%$ of mature coconut kernel consumption has been used in the form of coconut milk (Gwee, 1988), which contains not only lipids (41.5\%), but also carbohydrates $(5.2 \%)$, proteins $(4.5 \%)$, vitamin (vitamin B1, Niacin) and minerals (calcium, potassium, phosphorus and iron) (Pehowich, Gomes, Barnes, 2000). Other micronutrients such as Zeatin (Kobayashi et al., 1995; 1997) that are found to inhibit $\beta$-amyloid to prevent Alzheimer's disease(Froldi et al., 1999)and promote skin fibroblast proliferation(Rattan, Sodagam, 2005)were also reported. Thus, consumption of coconut milk might produce different effects from those taking pure coconut oil. There are few studies about coconut kernel consumption. Available reports are concerned with its effect on the plasma lipid profile and the results are still controversial. Padmakumaran et al.(1999)found that young male rats that consumed fresh coconut kernel alone or together with coconut oil had lower serum total cholesterol, HDL, VLDL and LDL-C but higher serum triglyceride. In contrast, Ekanayaka et al.(2013)studied human subjects and found that 8 -weeks consumption of coconut milk porridge caused lower plasma level of LDL with an increased HDL cholesterol. However, there is no report on the effects of coconut kernel consumption on vascular functions, in particular not for middle-aged individuals where the body functions start to decline. In addition, the methods for preparation of the coconut are inconsistent. Thus, the present studies were aimed to investigate whether chronic consumption of the lyophilized coconut milk, prepared from fresh mature coconut kernel without addition of any water or heating, would have any effects on vascular function in middle-aged rats using an impaired-endothelium function model (Chongsa, Kanokwiroon, Jansakul, 2015; Yorsin et al., 2014). Two dosages were used. 1 or $3 \mathrm{~g} / \mathrm{kg}$ coconut milk, these dosages being comparable (weight-adjusted) to the coconut milk content, respectively, of one serving of green curry and a full set of Thai dishes (a green curry, a chicken coconut soup, and a coconut dessert). Other side effects such as those on animal body weight and food intake, gross internal organ toxicity, body fat accumulation, fasting serum glucose and lipid profile and on the liver and renal functions were also investigated. The results obtained should be of value in determining if it might be an advantage to develop coconut milk as a health product for the aging human.

\section{MATERIAL AND METHODS}

\section{Coconut milk preparation}

Fresh mature coconut kernel was grated and directly compressed with an electric screw press machine to obtain a large sample of fresh aqueous coconut milk. The milk was then filtered through a cloth filter followed by lyophilisation to achieve a dried fresh coconut milk (CCM). It was kept at $-20^{\circ} \mathrm{C}$ until used.

\section{Analysis of dried fresh coconut milk composition}

Twenty grams of CCM were centrifuged at room temperature at $3000 \mathrm{rpm}$ for $15 \mathrm{~min}$, to achieve coconut oils and residues. The oil separated from CCM was measured with a separated graduated cylinder. The residues were collected and dissolved in distilled water and then the protein was precipitated with analytical grade acetone. The precipitated proteins were re-dissolved with distilled water and acetone removed by a rotary evaporator $\left(40^{\circ} \mathrm{C}\right)$ under reduced pressure and followed by lyophilisation to achieve dried CCM protein powder. The supernatant was collected, followed by rotary evaporation to get rid of the acetone, and then lyophilisation to achieve dried CCMsugar containing fractions.

The coconut oil was analyzed for its fatty acids composition by LC-MS (using the service of the Central Equipment Center, Prince of Songkla University).

The CCM protein powder was analyzed for its protein composition by 1D SDS-PAGE gel electrophoresis and comparison of the protein bands with the standard protein marker of 10.5 -175 kDa (Bio-RAD, USA).

The CCM-sugar containing fraction was analyzed for its total sugar content by the phenol sulfuric acid method (Dubois et al., 1956).

\section{Drugs}

The following drugs were used. Acetylcholine chloride, $N^{\mathrm{G}}$-nitro-L-arginine (L-NA), norepinephrine, phenylephrine hydrochloride, DL-propagylglycine (PAG), pentobarbital, and oil red O from Sigma, U.S.A. Acetylcholine chloride and phenylephrine were dissolved in a solution containing $\mathrm{NaCl} 9 \mathrm{~g} / \mathrm{L}, \mathrm{NaH}_{2} \mathrm{PO}_{4} 0.19 \mathrm{~g} / \mathrm{L}$ and ascorbic acid $0.03 \mathrm{~g} / \mathrm{L}$. Standard animal food contained 
crude protein, 24\%; Fat, $4.5 \%$; fiber, $5 \%$ and protein, $53.9 \%$ (Metabolizable energy about 3,040 kcal $/ \mathrm{kg}$, Perfect Companion Group Company, Thailand).

\section{Pharmacological studies}

Middle-aged (12-14 month old) Wistar male rats were provided from the Southern Laboratory Animal Facility, Faculty of Science, Prince of Songkla University. The animals were housed in controlled environmental conditions at $25^{\circ} \mathrm{C}$ on a $12 \mathrm{~h}$ dark and $12 \mathrm{~h}$ light cycle and allowed access to standard food and tap water ad libitum. The animal methods employed in this study were approved by the Prince of Songkla University Animal Ethics Committee (Ethic No. Ref. 08/54). The investigation conformed to the Guide for the Care and Use of Laboratory Animals. The rats were randomly selected into three groups, 6 animals for each group. The experimental group was treated by oral administration of 1 or $3 \mathrm{~g} / \mathrm{kg}$ CCM once a day for 6 weeks. The vehicle control groups received distilled water once a day using the same volume as that for the coconut milk ( $1 \mathrm{~mL} / \mathrm{kg}$ animal body weight) in the same period of 6 weeks. The body weight and $24 \mathrm{~h}$ food intake (one day before receiving oral gavage of the vehicle or coconut milk suspension) was recorded at day 0 , and again every consecutive $7^{\text {th }}$ day over the 6 -week period.In addition, the total daily intake of calories, carbohydrates ( $\mathrm{g} \mathrm{x} 4,000)$, lipids ( $\mathrm{g} \times 9,000)$ and proteins $(\mathrm{g} \times 4,000)$, of the $6^{\text {th }}$ week of control (food) and 1 or $3 \mathrm{~g} / \mathrm{kg} \mathrm{CCM}$-treated groups were calculated (including food and CCM 1 or $3 \mathrm{~g} / \mathrm{kg}$ ).

Effects of the coconut milk treatment on the basal blood pressure and on the haematology and clinical biochemical analysis

The same methods as previously described (Yorsin et al., 2014) were used. At the end of the 6 weeks, CCM or distilled treatment, each rat (13-15 h fasting) was anaesthetized with pentobarbital $(60 \mathrm{mg} / \mathrm{kg})$. A tracheal tube was inserted into the trachea, and a small polyethylene tube was cannulated into the right common carotid artery that had been connected to a pressure transducer and a Polygraph (P7D model, Grass Company) for blood pressure and heart rate recording. The data were collected after a 40-min equilibration period, by which time the basal blood pressure and heart rate of the animal became stable.

After measuring the basal blood pressure and heart rate, the rat was killed by decapitation with a guillotine, and $5 \mathrm{~mL}$ and $2 \mathrm{~mL}$ of blood samples were collected from the decapitated rat and placed in a glass test tube and a plastic test tube containing EDTA, respectively. The glass container with $5 \mathrm{~mL}$ of blood was left at room temperature for $30 \mathrm{~min}$ and then centrifuged at $1200 \mathrm{rpm}$ for $10 \mathrm{~min}$. The serum was then collected and kept at $-70{ }^{\circ} \mathrm{C}$ until measurements were made for the kidney and liver enzymes, and for glucose and lipid levels. These measurements were made by enzymatic methods using an automatic chemistry analyzer (Hitachi Modular P800, Germany) that was routinely operated at the Prince of Songkla University Hospital. They were carried out within 1 month of sample collection. The $2 \mathrm{~mL}$ of blood with EDTA was sent to the hematology laboratory for a total blood count procedure measured by an automated hematology analyzer (Celltac E, Model MEK-7222K, Japan).

\section{Effects of CCM treatment on internal organs and lipid accumulation}

The decapitated rat (after removing the thoracic aorta and mesenteric artery) was dissected as previously described (Yorsin et al., 2014). Heart, lung, liver, adrenal gland, kidney, testes; visceral fats from the epididymis, testis and retroperitoneal, and subcutaneous fats were removed and weighed using a MettlerPL2001-Lbalance (Mettler Toledo International Inc., Switzerland).

Two pieces of liver (middle lobe) were cut, embedded into a cryostat gel, the sections ( $20 \mu \mathrm{m}$ thick), stained with oil red $\mathrm{O}(0.5 \%$ in absolute propylene glycol), and mounted with glycerine jelly for observation by light microscopy. The oil red $\mathrm{O}$ of each slide was extracted with $1 \mathrm{~mL}$ of $100 \%$ dimethylsulfoxide (DMSO), and its absorbance was measured at $520 \mathrm{~nm}$ using a Thermo Fisher Scientific spectrophotometer (Model G10s UV-VIS, USA). The concentration of the oil red $\mathrm{O}$ was obtained from the standard curve of known concentrations of the oil red $\mathrm{O}$ in $100 \%$ DMSO $(\mu \mathrm{g} / \mathrm{mL})$. The area of a whole liver thin section was measured using the Auto CAD 2005 program. The amount of the accumulated liver lipid was expressed in terms of $\mu \mathrm{g} / \mathrm{mL} / \mathrm{cm}^{2}$ of the liver tissue thin section area.

\section{Preparation of the thoracic aortic rings}

The thoracic aorta was removed from the decapitated rat and placed in oxygenated $37^{\circ} \mathrm{C}$ Krebs-Henseleit solution, and then adhering connective tissue was carefully removed. Six adjacent rings of 4-5 $\mathrm{mm}$ in length were cut. For one ring the endothelium layer was removed by a small cotton bud. Each aortic ring was mounted with two stainless steel hooks in a 20-mL organ bath containing Krebs-Henseleit solution of the following composition (mM): $\mathrm{NaCl} 118.3, \mathrm{KCl} 4.7, \mathrm{CaCl}_{2} 1.9, \mathrm{MgSO}_{4} \cdot 7 \mathrm{H}_{2} \mathrm{O} 0.45$, $\mathrm{KH}_{2} \mathrm{PO}_{4} 1.18, \mathrm{NaHCO}_{3} 25.0$, glucose 11.66, $\mathrm{Na}_{2}$ EDTA 0.024 and ascorbic acid 0.09 , maintained at $37{ }^{\circ} \mathrm{C}$ and bubbled with carbogen $\left(95 \% \mathrm{O}_{2}\right.$ and $5 \% \mathrm{CO}_{2}$ gas mixture). One of the hooks was fixed at the bottom and the other 
was connected to a transducer for recording the isometric tension by a Polygraph. The tissues were equilibrated for 60 min under a resting tension of $1 \mathrm{~g}$ and the bath solution was replaced with pre-warmed oxygenated KrebsHenseleit solution every $15 \mathrm{~min}$.

At the end of the equilibration period, each aortic ring was tested for the viability of the endothelium by precontraction with phenylephrine $(3 \mu \mathrm{M})$ until the response reached a plateau (5-8 $\mathrm{min})$, and then addition of acetylcholine $(30 \mu \mathrm{M})$. Endothelial viability was judged by a $>65 \%$ vasorelaxation back to the tension generated by the ring before adding the phenylephrine. Denudation was confirmed by the absence of vasorelaxation following the response to the addition of acetylcholine. The preparations were then washed several times with Krebs-Henseleit solution, and allowed to fully relax for $45 \mathrm{~min}$ before the experimental protocol began.

\section{Effects of the coconut milk treatment on the pharmacological vascular functions}

\section{Role of nitric oxide}

At the end of the 45-min re-equilibration after the functional endothelium testing, the basal tension of the thoracic aortic rings with intact endothelium and the rings without endothelium was adjusted to the optimal tension of $2 \mathrm{~g}$ and equilibrated for another $10 \mathrm{~min}$, and then the contractile response to a cumulative concentrationresponse $(C-R)$ curve of phenylephrine was obtained. This was followed by several washings, and the aortic ring was allowed to fully relax for $50 \mathrm{~min}$. Then the endotheliumintact aortic rings were preincubated with L-NA for 40 min, and then the second $C-R$ curve to phenylephrine was obtained.

Using another set of endothelium-intact thoracic aortic rings, each ring was equilibrated under a basal tension of $2 \mathrm{~g}$ for $10 \mathrm{~min}$, and was then precontracted with phenylephrine $(3 \mu \mathrm{M})$ for $10-15$ min (plateau) followed by determination of the cumulative dilator $C-R$ curves to acetylcholine. Following several washings and reequilibration for $40 \mathrm{~min}$, the aortic rings were preincubated with L-NA for $40 \mathrm{~min}$, and the second $C-R$ curve to acetylcholine obtained in the same manner as above

\section{Role of $\mathrm{H}_{2} \mathrm{~S}$}

After equilibration, the endothelium-intact thoracic aortic rings were incubated with L-NA for 40 min under a basal tension of $3 \mathrm{~g}$. Then a cumulative $C-R$ curve to phenylephrine was obtained in the presence of L-NA, followed by several washings and re-equilibration for $60 \mathrm{~min}$ in the presence of L-NA to allow full relaxation of the blood vessels to their original baseline of $3 \mathrm{~g}$. After that, DL-propargylglycine ( $\mathrm{PAG}, \mathrm{a}_{2} \mathrm{~S}$ inhibitor) was added into the incubation and left for 10-15 min until the aortic contraction reached a plateau, and the cumulative $C-R$ curve to phenylephrine was obtained in the presence of L-NA and PAG.

\section{eNOS and CSE Western blot analysis}

To analyze the expression of the eNOS and CSE enzyme, the thoracic aorta of the CCM-treated and the distilled water control groups $(n=4)$ were harvested and kept at $-70^{\circ} \mathrm{C}$ until used. Protein extraction from the tissues and Western blot analysis were carried out as previously described (Yorsin et al., 2014). Briefly, each tissue from each animal was chopped on ice and homogenized in lysis buffer with $25 \mathrm{mM}$ Tris-HCl, pH 7.6, $150 \mathrm{mM}$ $\mathrm{NaCl}, 1 \% \mathrm{NP}-40,1 \%$ sodium deoxycholate, $0.1 \%$ SDS, $0.5 \mathrm{mM}$ EDTA and the protease inhibitor cocktail (GE Healthcare), centrifuged, and the total protein measured in the supernatants by the Biorad protein assay method. $50 \mu \mathrm{g}$ of protein was electrophoretically separated on $12 \%$ polyacrylamide-SDS gels and the proteins were transferred onto a nitrocellulose membrane. Nonspecific-binding sites were blocked with $5 \%$ low fat dry milk in TBS-T (Tris buffer saline- $0.1 \%$ Tween 20 ) and then incubated with primary antibodies against eNOS (1:250), CSE $(1: 1,000)$ and $\beta$-actin $(1: 1,000)$ antibodies dissolved in $1 \%$ low fat dry milk in TBS-T overnight at $4^{\circ} \mathrm{C}$ [rabbit eNOS and rabbit $\beta$-actin antibodies were from Cell Signaling (U.S.A); mouse CSE was from Abnova (U.S.A)]. Membranes were incubated with horseradish-peroxidase anti-rabbit IgG antibody diluted to $1: 5,000$ (eNOS and $\beta$-actin) and horseradish-peroxidase anti-mouse IgG antibody diluted to $1: 5,000$ (CSE) in 1\% low fat dry milk in TBS-T for $1 \mathrm{~h}$. After being washed with TBS-T three times, the proteins were detected by an ECL chemiluminescent detection kit (Pierce), and the reaction was visualized by a chemiluminescence imaging instrument (Vilber Lourmat, France). The intensity of the bands was analyzed using the Fusion Capt Advance quantitation analysis program. To ensure equal protein loading, results were normalized to the $\beta$-actin protein expression and expressed as units relative to the $\beta$-actin densitometry.

\section{Statistical analysis}

The results were expressed as the mean \pm standard error of the mean $(\mathrm{SEM})(\mathrm{n}=6$ for vascular function study and $n=4$ for Western blotting). " $n$ " is the number of animals. Statistical differences were determined by the Student's unpaired $t$-test or by one-way analysis of variance (ANOVA), followed by Tukey's range test using 
6 weeks consumption of pure fresh coconut milk caused up-regulation of eNOS and CSE protein expression in middle-aged male rats

GraphPad Prism 5.00. AP value $<0.05$ was considered to identify a significant difference between values.

\section{RESULTS}

\section{Coconut milk yield and chemical composition}

Dried fresh coconut milk prepared directly by compressed grated mature coconut kernel, CCM, yielding $16.7 \%$ of the fresh grated matured coconut kernel. Total lipid, protein and sugar content in percent of the CCM were70.08, 19.35 and 5.34, respectively. Protein profile of the CCM, assessed by 1D SDS page gel electrophoresis, showed 7 major bands at the molecular weight about 14-51 kDa (Figure 1). Fatty acid composition of the oil in the CCM is shown in Table I. The CCM contained medium-chain fatty acid $\left(\mathrm{C}_{8}-\mathrm{C}_{12}\right)$, lauric acid $(40 \%)$, caprylic acid and capric acid (5\%); long-chain fatty acid $\left(>\mathrm{C}_{12}\right)$, myristic acid $(17 \%)$ and palmitic acid (7\%); and $\omega$-6-unsaturated fatty acid, linoleic acid (1\%).

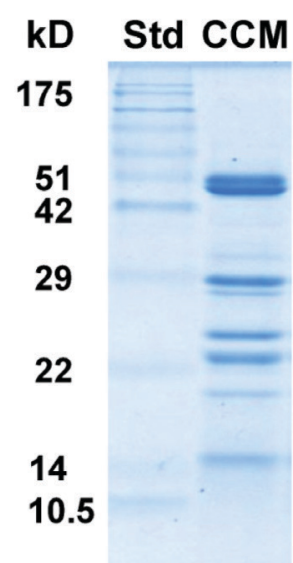

FIGURE 1 - SDS-PAGEgel electrophoresis from standard marker protein (Bio-Rad, USA) and CCM. Lane 1 is MW standards.

\section{Effects of 6-week coconut milk treatment on the body weight, food intake, animal blood pressure, internal organs and adipose tissue and blood chemistry}

No changes in body weight were found with either 1 or $3 \mathrm{~g} / \mathrm{kg}$ CCM treatment, although food intake (standard rat chow in $\mathrm{g} / \mathrm{animal} / \mathrm{day}$ ) of the $3 \mathrm{~g} / \mathrm{kg} \mathrm{CCM}$ treatment was markedly (24\%) decreased, when compared to that of the distilled water control group (Figure 2). However, when the daily rat chow- and CCM-intake were calculated in term of calories, carbohydrate, fat and protein, at the end of treatment ( $6^{\text {th }}$ week), the total daily calories of food intake
TABLE I - Fatty acids composition (in percent) of CCM oils obtained from the CCM

\begin{tabular}{llc}
\hline Fatty acid name & & \% in CCM oil \\
\hline Caprylic acid & (C8:0), MCF & $1.05 \pm 0.00$ \\
Capric acid & (C10:0), MCF & $3.55 \pm 0.00$ \\
Lauric acid & (C12:0), MCF & $40.68 \pm 0.08$ \\
Myristic acid & (C14:0), LCF & $17.53 \pm 0.02$ \\
Palmitic acid & (C16:0), LCF & $7.89 \pm 0.00$ \\
Stearic acid & (C18:0), LCF & $2.87 \pm 0.00$ \\
Oleic acid & (C18:1), LCF & $4.65 \pm 0.00$ \\
Linoleic acid & (C18:2), LCF & $1.01 \pm 0.00$ \\
\hline
\end{tabular}

Values are expressed as mean $\pm \mathrm{STD} ; \mathrm{n}=3$. MCF, medium chain fatty acid; LCF, long chain fatty acid

of $1 \mathrm{~g} / \mathrm{kg} \mathrm{CCM}$ treatment group $(5.8 \pm 0.3 \mathrm{kcal}$, standard rat chow $+\mathrm{CCM}$ intake) and $3 \mathrm{~g} / \mathrm{kg}$ CCM treatment group $(5.3 \pm 0.6 \mathrm{kcal}$, standard rat chow + CCM intake $)$ were in the same level as that of the distilled water control group (5.2 $\pm 0.2 \mathrm{kcal}$, standard rat chow). Basal systolic and diastolic pressure and the basal heart rate of anaesthetized rats were similar between the CCM-and the distilled water treated rats (Table I suppl.). None of the internal organs, visceral and subcutaneous adipose tissue weight, liver cell lipid accumulation or the total blood cell count, was found to be altered after the CCM treatment ( 1 and $3 \mathrm{~g} / \mathrm{kg}$ ) compared to the distilled water control group (Table II-IV suppl., Figure 1 Suppl.). At the dosage of $1 \mathrm{~g} / \mathrm{kg}, \mathrm{CCM}$ caused no changes either in fasting serum glucose and lipids profile (Table II). When the dosage was increased to $3 \mathrm{~g} / \mathrm{kg}$, CCM caused lowering in fasting plasma glucose. The other biochemical parameters studied were not different between the CCM and the distilled water control rats (Table V suppl.).

\section{Effects of CCM-treated rats on vascular functions}

\section{Effect on contraction and relaxation of the thoracic} aorta

At the dosage of $1 \mathrm{~g} / \mathrm{kg}$ of CCM treatment did not alter vascular activity of the middle-aged rat to phenylephrine and acetylcholine. However, when the dosage of CCM treatment was increased to $3 \mathrm{~g} / \mathrm{kg}$, the maximal contractile response to phenylephrine of the intact endothelium aortic rings was lower than that of the vehicle control group. Pretreatment of the intact-aortic rings with L-NA caused an increase in maximal contractile responses of the aortic rings to phenylephrine to the same extent as that of the vehicle control group with a decrease in $\mathrm{EC}_{50}$ values of both groups (Figure $3 \mathrm{~A}$ and $\mathrm{B}$ and Table VI suppl.). Denudation of the aortic ring also caused an 

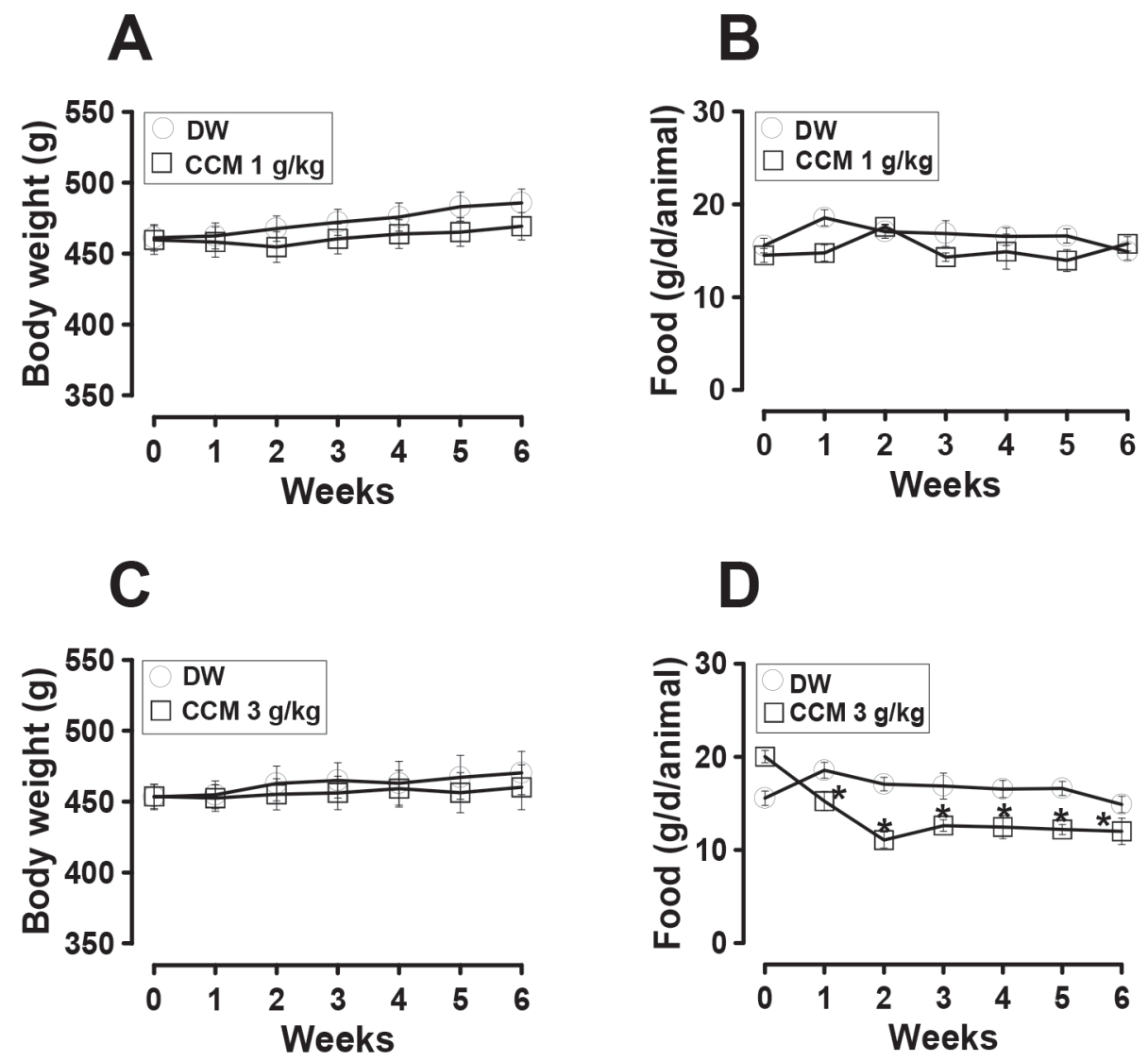

FIGURE 2 - The body weight (left) and food consumption (right) of middle age male rats receiving distilled water (DW) or CCM (1 or $3 \mathrm{~g} / \mathrm{kg}$ ), once a day for 6 weeks. Values represent mean $\pm \mathrm{SEM} ; \mathrm{n}=6$. * Significantly lower than distilled water control group,P<0.05.

TABLE II - Effects of CCM $(1,3 \mathrm{~g} / \mathrm{kg})$ or distilled water (control) consumption for 6 weeks on the fasting levels of serum glucose and lipids of middle-aged male rats

\begin{tabular}{lccccc}
\hline NLAC- MU & Glucose & Triglyceride & Cholesterol & HDL-C & LDL-C \\
\hline Normal range (mg/dL) & $122.10-180.80$ & $61.00-164.00$ & $46.00-98.00$ & - & - \\
Control & $137.69 \pm 5.65$ & $73.41 \pm 8.59$ & $76.71 \pm 5.61$ & $61.51 \pm 4.96$ & $12.05 \pm 1.41$ \\
CCM 1 g/kg & $124.33 \pm 5.83$ & $101.67 \pm 15.27$ & $73.17 \pm 1.64$ & $62.08 \pm 1.02$ & $9.57 \pm 1.03$ \\
CCM 3 g/kg & $115.40 \pm 5.96^{\mathrm{a}}$ & $66.40 \pm 6.98$ & $73.40 \pm 3.61$ & $62.00 \pm 2.49$ & $13.23 \pm 2.04$ \\
\hline
\end{tabular}

Values are expressed as mean $\pm \mathrm{SEM} ; \mathrm{n}=6 .{ }^{\mathrm{a}}$ Significantly lower than control group, $\mathrm{P}<0.05$.

Note: NLAC-MU normal range $=$ National Laboratory Animal Centre, Mahidol University normal range. HDL-C $=$ High Density Lipoprotein cholesterol and LDL-C $=$ Low Density lipoprotein cholesterol.

increase in maximal contractile response to phenylephrine of the CCM-treated aortic rings to the same extent as that of the vehicle control group whether L-NA presented or not (Figure3C and D).

The relative relaxation to acetylcholine of aortic rings precontracted with phenylephrine was greater for the aortic rings obtained from the $3 \mathrm{~g} / \mathrm{kg}$, but not the $1 \mathrm{~g} / \mathrm{kg}$, CCMtreated-compared to that of the distilled water control group, and this effect was abolished by pre-incubating the aortic ring with L-NA (Figure 4 and Table VII suppl.).
Role of $\mathrm{H}_{2} \mathrm{~S}$

Addition of PAG to the incubation medium caused a spontaneous contraction of the thoracic aortic rings for all groups. However, those obtained from $3 \mathrm{~g} / \mathrm{kg}$ CCM $(3.89 \pm 0.62 \mathrm{~g})$ were higher than those from $1 \mathrm{~g} / \mathrm{kg} \mathrm{CCM}(1.06 \pm 0.43 \mathrm{~g})$, which were higher than those of the distilled water control group $(0.38 \pm 0.006 \mathrm{~g})$. These effects subsequently resulted in a greater contraction for low concentrations of the phenylephrine $C-R$ curves of the thoracic aortic rings obtained from 

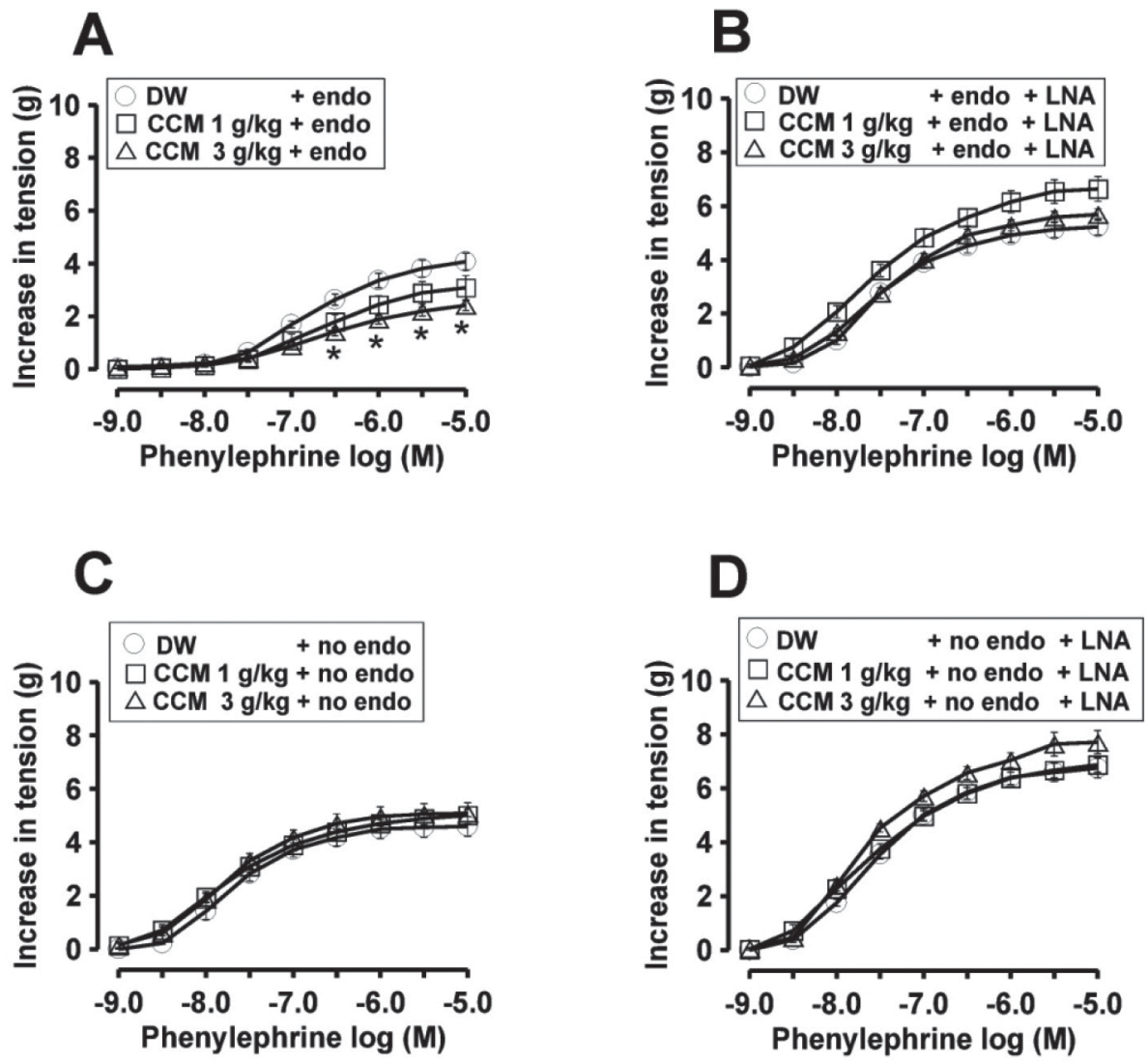

FIGURE 3 - Effects of 6 weeks of oral administration of CCM (1 or $3 \mathrm{~g} / \mathrm{kg}$ ) or distilled water (DW, control) on contractile response to phenylephrine of endothelium-intact (endo, A), endothelium-intact with L-NA(B), without endothelium (no endo, C), or without endothelium with L-NA (D) thoracic aorta. Values represent mean \pm SEM; $n=6$. ${ }^{*}$ Significantly lower than that of the distilled water control group, $\mathrm{P}<0.05$.

CCM-treated rats than that of the vehicle control group (Figure5).

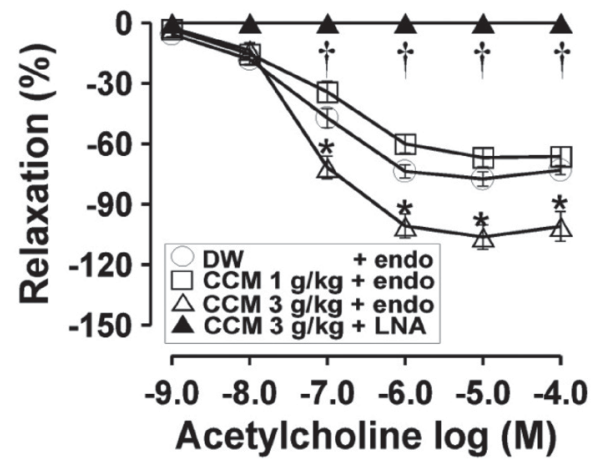

FIGURE 4 - Effect of 6 weeks oral gavage of CCM(1 or $3 \mathrm{~g} / \mathrm{kg}$ ) or distilled water (DW, control) on relaxation of the endothelium-intact thoracic aortic ring precontracted with phenylephrine to acetylcholine before and after pre-incubation with L-NA (CCM $3 \mathrm{~g} / \mathrm{kg}+\mathrm{L}-\mathrm{NA})$. Values represent mean \pm SEM; $n=6$. *Significantly lower than the other groups and 'significantly higher than the other groups, $\mathrm{P}<0.05$.

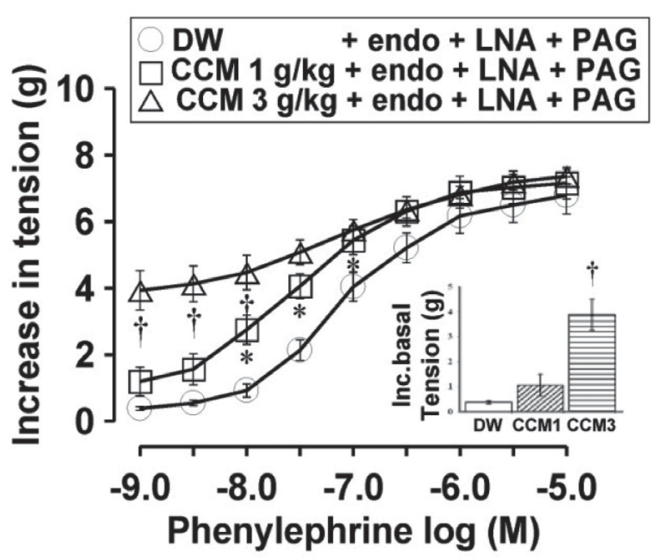

FIGURE 5 - Effects of 6 weeks oral administration of CCM (1 or $3 \mathrm{~g} / \mathrm{kg}$ ) or distilled water (DW, control) on the contractile response to phenylephrine of L-NA pretreated endotheliumintact (endo) thoracic aortic rings in the presence of PAG. Values represent mean \pm SEM; $n=6$. *Significantly higher than the control groups and "significantly higher than the other groups, $\mathrm{P}<0.05$. Note: Miniature bar graphs in Figure 5 showed the increased basal tension after addition of the PAG. 

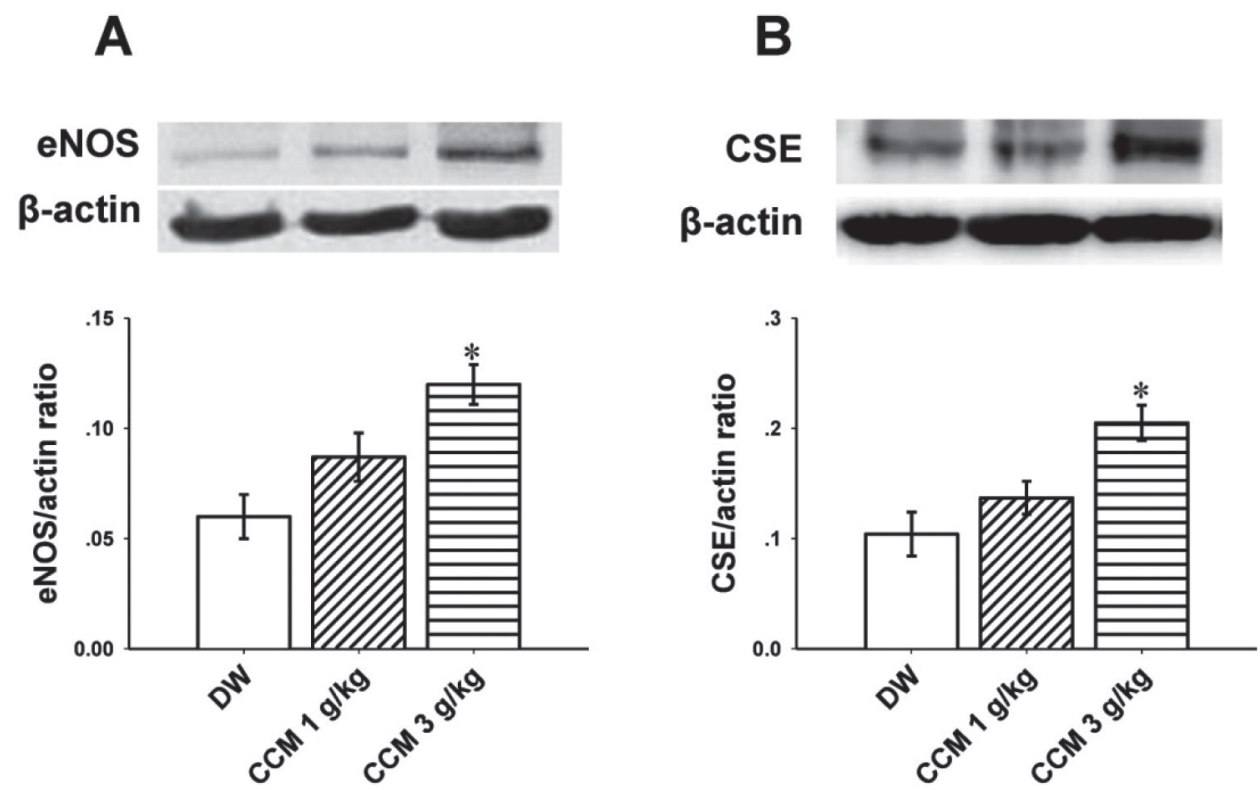

FIGURE 6 - The effect of 6 weeks oral administration of CCM $(1$ or $3 \mathrm{~g} / \mathrm{kg})$ or distilled water on eNOS (A) and CSE (B) protein expression of the thoracic aorta compared to a distilled water control group (DW). For each blot, $\beta$-actin expression is shown as a loading control. Values represent as mean $\pm \mathrm{SEM} ; \mathrm{n}=4$. *Significantly higher than the other groups, $\mathrm{P}<0.05$.

\section{eNOS and CSE Western blot analysis}

The quantitative expression of the eNOS and CSE proteins as determined by Western blotting from the isolated thoracic aorta was significantly higher for those obtained from the $3 \mathrm{~g} / \mathrm{kg}$ CCM-treated rat compared to that of the vehicle control groups (Figure6A and B). Although at the dosage of $1 \mathrm{~g} / \mathrm{kg}$ CCM treated rats also showed a trend to an increase of both the eNOS and the CSE proteins, it did not reach statistical significance.

\section{DISCUSSION}

The present study demonstrated that consumption of the CCM caused beneficial effects on the cardiovascular system if consumed in a sufficient amount. As shown in the results section, consumption of the CCM at a dosage of 1 $\mathrm{g} / \mathrm{kg}$ for 6 weeks by the middle-aged rats did not result in any difference in the parameters studied. When the dosage was increased to $3 \mathrm{~g} / \mathrm{kg}$, CCM caused lowered food intake. The reduction in food intake was not associated with any change in body weight or in the weight of the organs measured. The reasons for this might be due to high lipid content $(70 \%)$ of the CCM composition which consists dominantly of medium chain fatty acids (8: 0 to 12: 0 ; $45 \%$ ). These fatty acids are absorbed directly to the portal vein except for lauric acid (C12:0) that is partly absorbed via the lymphatic system (Mu, Hoy, 2000; 2001; 2002). More recently, Valente et al. (2017) reported that coconut oil consumption promoted less appetite in women with excess body fat. In addition, Jambor de Sousa et al. (2006) found that hepatic portal vein infusion of caprylic acid, a medium chain fatty acid, caused reduction of food intake by about $40 \%$ in 18 -h food-deprived male rats. Another possibility is that CCM might contain an active substance that at high doses it causes satiety or reduced appetite resulting in reduced food intake. However, further specific studies would be needed to clarify these possibilities.

The alteration in vascular function, especially endothelial function, is the key event in the pathophysiology of atherosclerosis, as it was shown that endothelial dysfunction preceded and predicted atherosclerosis (Bonetti, Lerman, Lerman, 2003; Davignon,Ganz, 2004).In the present study endothelial dysfunction of the middle-aged male rat(Chongsa et al., 2015) was used to study the effects of chronic consumption of the CCM. Although there were no changes in animal blood pressure and heart rate after taking CCM compared to the distilled water control group, adosage of $3 \mathrm{~g} / \mathrm{kg}$ but not $1 \mathrm{~g} / \mathrm{kg}$ of CCM, caused some beneficial changes in vascular function. These included reduction in maximal contractile response of thoracic aortic rings to phenylephrine and a higher maximal relaxation to acetylcholine. These effects were abolished by L-NA or removal of the endothelium, which indicates that the lowering of maximal contractile response to phenylephrine of the CCM-treated aortic rings might be due to an increase in nitric oxide production from the vascular endothelium. This was confirmed by the finding that eNOS protein expression of the thoracic aorta 
obtained from CCM-treated was higher than that of the control rats.Salil, Nevin, Rajamohan $(2011,2012)$ reported that coconut kernel protein is rich in arginine which was able to rescue the pancreatic $\beta$-cells and cytoarchitecture in alloxan-induced diabetic Wistar Albino rat via the arginine-nitric oxide pathway. Thus, it is possible that the up-regulation of the vascular eNOS of the CCM treated middle-aged rat in the present study might be mediated by the coconut protein. However, further study of the isolated CCM protein consumption by the middle-aged rat would be needed to clarify this possibility.

It has been reported that high-fat diet consumption by young rats or mice for 12-14 weeks causes deficiency of aortic CSE and $\mathrm{H}_{2} \mathrm{~S}$ (Jenkins, Nguyen, Hart, 2016; Peh et al., 2014). Thus, it is possible that chronic consumption by the middle-aged rat of the CCM which contained high content of coconut oil might affect blood vessel $\mathrm{H}_{2} \mathrm{~S}$ production. To test this possibility another set of the endothelium-intactaortic rings was used and preincubated with L-NA in order to inhibit eNOS activity in order to prevent any disturbances by nitric oxide before adding PAG, a cystathionine- $\gamma$-lyase inhibitor; the vasocontraction to phenylephrine was then determined. As shown in the results section, adding PAG to the incubation medium caused a greater increase in basal baseline tension of the aortic rings obtained from CCM-treated rats than that of the control group, suggesting that the activity of the CSE enzyme of the CCM-treated rats was higher than that of the control rats. These results sequentially caused an increase in contractile response to low concentrations of the phenylephrine on the aortic rings that was higher than that of the control group. The finding that the blood vessel CSE protein expression was higher in the CCM treated rats is consistent with the finding that consumption of CCM caused an increase in blood vessel $\mathrm{H}_{2} \mathrm{~S}$ production. This result is in contrast to those of the Jenkins, Nguyen, Hart(2016) and Peh et al.(2014) who found that high fat diet caused a decrease in vascular $\mathrm{CSE}$ and $\mathrm{H}_{2} \mathrm{~S}$ production. The reason for this might be the differences in the types of fatty acid used. In the present study we used CCM which contained mostly medium-chain fatty acid which was found to cause an increase in mitochondrial and peroxisomal $\beta$-oxidation of fatty acids (Arunima, Rajamohan, 2014). In contrast, Jenkins, Nguyen, Hart (2016) and Peh et al.(2014) used western diet and high fat diet, respectively, which contained mostly long-chain fatty acid, which was found to induce vascular oxidative stress and reduce endothelial function. As another possibility, Zhao et al. (2001) found that endogenous $\mathrm{H}_{2} \mathrm{~S}$ production from different vascular tissues including thoracic aorta was enhanced by the NO. Thus, the increased CSE protein expression which resulted in an increased $\mathrm{H}_{2} \mathrm{~S}$ production in the present study might be facilitated by the increased NO production elicited by the CCM, as mentioned above. However, further study is needed to clarify these possibilities.

In the present study it was also found that chronic consumption of CCM caused a slight decrease in basal fasting plasma glucose compared to that of the control group. As mentioned above, the reason for this might be due to the increase in basal level of NO since it has been reported that low concentration of NO exerted positive regulation of insulin sensitivity and secretion (Carvalho et al., 2016; Kurohane Kaneko, Ishikawa, 2013). However, to clarify this possibility, further studyto measure basal plasma insulin level and/or the glucose insulin sensitivity of the CCM-treated and the control middle-aged rats would be necessary.

Taken together, consumption of CCM at the dosage of $3 \mathrm{~g} / \mathrm{kg}$ increased blood vessel eNOS and CSE protein expression resulting in increased $\mathrm{NO}$ and $\mathrm{H}_{2} \mathrm{~S}$ production to attenuate the contractile response of thoracic aortic rings to phenylephrine and potentiate vasodilatation to acetylcholine, all of which could be expected to prolong vascular health of the middle-aged rat. In addition, CCM consumption caused lowering of plasma glucose level with no harm to liver or kidney functions, or on fat metabolism. Thus, CCM could be a novel food to develop as a nutraceutical for vascular health of the aging human being. Nevertheless, further work is required to identify the mechanism that causes CCM to lower plasma glucose and the vascular effects described.

\section{Limitations of the study}

The present study did not show whether firstly, CCM consumption by the middle-aged rat has long-term effect. Therefore, the next investigation would be to determine by which time the vascular effects of CCM consumption disappear after quitting CCM consumption, and by which time it is recovered after renewing consumption. Secondly the studies did not measure insulin secretion, and this should be part of future studies.

\section{ACKNOWLEDGEMENTS}

This work was supported by Prince of Songkla University (SCI560140S) and the TRF Research Scholar fund (RSA59), Thailand. The authors thank Miss. Srisurat Duangsai for her technical assistance and Dr. Alan Guiter, Prince of Songkla University, for English assistance and Prof. Michael J. Mulvany, Aarhus University, Denmark, for his valuable comments and editing the manuscript. 


\section{CONFLICTS OF INTEREST}

The authors declare no conflict of interest.

\section{REFERENCES}

Abe K, Kimura H. The possible role of hydrogen sulfide as an endogenous neuromodulator. J Neurosci. 1996;16(3):1066-71.

Aquaro GD, Cagnolo A, Tiwari KK, Todiere G, Bevilacqua S, Di Bella G, Ait-Ali, L, Festa P, Glauber M, Lombardi M. Age-dependent changes in elastic properties of thoracic aorta evaluated by magnetic resonance in normal subjects. Interact Cardiovasc Thorac Surg. 2013;17(4):674-9.

Arunima S, Rajamohan T. Influence of virgin coconut oilenriched diet on the transcriptional regulation of fatty acid synthesis and oxidation in rats - a comparative study. $\mathrm{Br}$ J Nutrition. 2014;111(10):1782-90.

Avolio AP, Chen SG, Wang RP, Zhang CL, Li MF, O'Rourke MF. Effects of aging on changing arterial compliance and left ventricular load in a northern Chinese urban community. Circulation. 1983;68(1):50-8.

Bhayadia R, Schmidt BM, Melk A, Homme M. Senescenceinduced oxidative stresscauses endothelial dysfunction. J Gerontol Series A Biol Sci.2015;71(2):1-9.

Bonetti PO, Lerman LO, Lerman A. Endothelial dysfunction: a marker of atherosclerotic risk.Arterioscler Thromb Vasc Biol. 2003;23(2):168-75.

Carvalho DS, Diniz MM, Haidar AA, Cavanal MF, da Silva Alves E, Carpinelli AR, et al. L-Arginine supplementation improves insulin sensitivity and beta cell function in the offspring of diabetic rats through AKT and PDX-1 activation. Eur J Pharmacol. 2016;791:780-7.

Chongsa W, Kanokwiroon K, Jansakul C. Effects of 6 weeks oral administration of Phyllanthus acidus leaf water extract on the vascular functions of middle-aged male rats. J Ethnopharmacol. 2015;176:79-89.

Collins JA, Munoz JV, Patel TR, Loukas M, Tubbs RS. The anatomy of the aging aorta. Clin Anat. 2014;27(3):463-6.

Davignon J, Ganz P. Role of endothelial dysfunction in atherosclerosis. Circulation. 2004;109(23 Suppl 1):III27-32.
Dubois M, Gilles KA, Hamilton JK, Rebers PA, Smith F. Colorimetric method for determination of sugars and related substances. Anal Chem.1956;28(3):350-6.

Ekanayaka RA, Ekanayaka NK, Perera B, De Silva PG. Impact of a traditional dietary supplement with coconut milk and soya milk on the lipid profile in normal free living subjects. J Nutr Metab. 2013;2013:481068.

Froldi G, Gallo U, Ragazzi E, Caparrotta L. 6-Benzylaminopurine: a plant derived cytokinin inducing positive inotropism by P2purinoceptors. Planta Med. 1999;65(3):245-9.

Gwee CN. New technologies open the passage into new usage of coconut milk products.In: Maneepun S, Varangoon P, Phitakpol B (editors). Food Science and Technology in Industrial Development. Bangkok: Institute of Food Research and Product Development, Kasetsart University; 1988. v. 1, p. 157-62.

Hosoki R, Matsuki N, Kimura H. The possible role of hydrogen sulfide as an endogenous smooth muscle relaxant in synergy with nitric oxide. Biochem Biophys Res Comm. 1997;237(3):527-31.

Jambor de Sousa UL, Arnold M, Langhans W, Geary N, Leonhardt M. Caprylic acid infusion acts in the liver to decrease food intake in rats. Physiol Behav. 2006;87(2):388-95.

Jenkins TA, Nguyen JCD, Hart JL. Decreased vascular $\mathrm{H}_{2} \mathrm{~S}$ production is associated with vascular oxidative stress in rats fed a high-fat western diet. Naunyn-Schmiedeberg's Arch Pharmacol. 2016;389(7):783-90.

Kobayashi H, Morisaki N, Hashimoto Y, Iwasaki S, Kawachi E, Nagata R, Shudo K. Identification of a major cytokinin in coconut milk. Experientia. 1995;15(11):1081-4.

Kobayashi H, Morisaki N, Tago Y, Hashimoto Y, Iwasaki S, Kawachi E, Nagata R, Shudo K. Structural identification of a major cytokinin in coconut milk as 14-O-(3-O- 19 [beta-Dgalactopyranosyl-(1--2)-alpha-D-galactopyranosyl-(1-3)-alphaL-arabinofuranosyl]-4-O-(alpha-L-arabinofuranosyl)-betad-galactopyranosyl)-trans-zeatin riboside. Chem Pharm Bull (Tokyo). 1997;45(2):260-4.

Kurohane Kaneko Y, Ishikawa T. Dual role of nitric oxide in pancreatic beta-cells. J Pharmacol Sci. 2013;123(4):295-300.

Lakatta EG. Cardiovascular ageing in health sets the stage for cardiovascular disease. Heart Lung Circul. 2002;11(2):76-91. 
Lakatta EG. So! What's aging? Is cardiovascular aging a disease? J Mol Cell Cardiol. 2015;83:1-13.

Lakatta EG, Levy D. Arterial and cardiac aging: major shareholders in cardiovascular disease enterprises: Part I: aging arteries: a "set up" for vascular disease. Circulation. 2003;107(1):139-46.

Marchesi S, Lupattelli G, Siepi D, Schillaci G, Vaudo G, Roscini AR, Sinzinger H, Mannarino E. Short-term atorvastatin treatment improves endothelial function in hypercholesterolemic women. J Cardiovasc Pharmacol. 2000;36(5):617-21.

$\mathrm{Mu} \mathrm{H}$, Hoy CE. Effects of different medium-chain fatty acids on intestinal absorption of structured triacyglycerols. Lipids. 2000;35(1):83-89.

$\mathrm{Mu} \mathrm{H}$, Hoy CE. Intestinal absorption of specific structured triacylglycerols. J Lipid Res. 2001;42(5):792-98.

Mu H, Hoy CE. Distribution of medium-chain FA in different lipid classes after administration of specific structured TAG in rats. Lipids. 2002;37(3):329-31.

National Institute on Aging (NIA). Global health and aging. NIH publication no. 11-7737 October 2011 neuromodulator. J Neurosci. 2011;16:1066-71.

Novella S, Dantas AP, Segarra G, Vidal-Gomez X, Mompeon A, Garabito M, Hermenegildo C, Medina P. Aging-related endothelial dysfunction in the aorta from female senescenceaccelerated mice is associated with decreased nitric oxide synthase expression. Exp Gerontol. 2013;48(11):1329-37.

Padmakumaran Nair KG, Rajamohan T, Kurup PA. Coconut kernel protein modifies the effect of coconut oil on serum lipids. Plant Foods Hum Nutr. 1999;53(2):133-44.

Peh MT, Anwar AB, Ng DSW, Atan MSBM, Kumar SD, Moore PK. Effect of feeding a high fat diet on hydrogen sulfide $\left(\mathrm{H}_{2} \mathrm{~S}\right)$ metabolism in the mouse. Nitric Oxide. 2014;41:138-45.

Pehowich DJ, Gomes AV, Barnes JA. Fatty acid composition and possible health effects of coconut constituents. West Indian Med J. 2000;49(2):128-33.

Rattan SIS, Sodagam L. Gerontomodulatory and youthpreserving effects of zeatin on human skin fibroblasts undergoing aging in vitro. Rejuvenation Res. 2005;8(1):46-57.
Rudolph TK, Ruempler K, Schwedhelm E, Tan-Andresen J, Riederer U, Boger RH, MaasR. Acute effects of various fastfood meals on vascular function and cardiovascular disease risk markers: the Hamburg Burger Trial. Am J Clin Nutrition. 2007;86(2):334-40.

Salil G, Nevin KG, Rajamohan T. Arginine rich coconut kernel protein modulates diabetes in alloxan treated rats. Chem-Biol Interact. 2011;189(1-2):107-11.

Salil G, Nevin KG, Rajamohan T. Arginine-rich coconut kernel diet influences nitric oxide synthase activity in alloxan diabetic rats. J Sci Food Agric. 2012;92(9):1903-8.

United Nation. UN. World population aging 2013. United State, New York; 2013.

Vaitkevicius PV, Fleg JL, Engel JH, O’Connor FC, Wright JG, Lakatta LE, Yin FC, Lakatta EG. Effects of age and aerobic capacity on arterial stiffness in healthy adults. Circulation. 1993;88(4Pt.1):1456-62.

Valente FX, Candido FG, Lopes LL, Dias DM, Carvalho SD, Pereira PF, et al. Effects of coconut oil consumption on energy metabolism, cardiometabolic risk markers, and appetitive responses in women with excess body fat. Eur J Nutr. 2017.Doi: 10.1007/s00394-017-1448-5. [Epub ahead of print].

Yang G, Wu L, Jiang B, Yang W, Qi J, Cao K, Meng Q, Mustafa $\mathrm{AK}, \mathrm{Mu} \mathrm{W}$, Zhang $\mathrm{S}$, et al. $\mathrm{H}_{2} \mathrm{~S}$ as a physiologic vasorelaxant: hypertension in mice with deletion of cystathionine gammalyase. Science. 2008;322(5901):587-90.

Yazdanyar A, Newman AB. The burden of cardiovascular disease in the elderly: morbidity, mortality, and costs. Clin Geriat Med. 2009;25(4):563-77.vii.

Yorsin S, Kanokwiroon K, Radenahmad N, Jansakul C. Effects of Kaempferia parviflora rhizomes dichloromethane extract on vascular functions in middle-aged male rat. J Ethnopharmacol. 2014;156:162-74.

Zhao W, Zhang J, Lu Y, Wang R. The vasorelaxant effect of $\mathrm{H}_{2} \mathrm{~S}$ as a novel endogenous gaseous KATP channel opener. EMBO J. 2001;20(21):6008-16.

Received for publication on $06^{\text {th }}$ May 2017 Accepted for publication on $19^{\text {th }}$ January 2018 